\section{When and how brands affect importance of product attributes in consumer decision process}

\section{Brand's impact on attribute importance}

\author{
Hyun Young Park
}

Department of Marketing, China Europe International Business School, Shanghai, China, and

Sue Ryung Chang

School of Business, Yonsei University, Seoul, Republic of Korea

\begin{abstract}
Purpose - This research investigates when and how brands influence attribute importance weights. Most past studies modelling consumer decision processes treated the brand of a product as an attribute parallel to the price, color or size of a product, and as a result, those studies assigned an equal (i.e. non-contingent) importance weight across brands for each attribute. In contrast, this study introduces a brand-contingent attribute-weighting process, in which brand is a higher-order construct that influences attribute importance.

Design/methodology/approach - This study presents a multi-level choice model in which the importance weight of an attribute can vary across brands. This study then estimates the model using real purchase data and survey data from an airline industry.

Findings - This study finds that attribute importance weights are contingent upon two aspects of a brand the perceived relative position of the brand and consumers' brand usage experiences. Specifically, when consumers perceive a brand to be inferior to its competitors in a given attribute, they generally place greater weight on that attribute for that brand. In contrast, when consumers perceive a brand to be superior to its competitors in a given attribute, only consumers with extensive brand usage experiences place greater weight on that attribute for that brand.

Practical implications - The findings provide managerial insights on brand positioning and segmentation strategies using consumers' brand usage experiences.

Originality/Value - This study advances the literature on consumer decision processes by modeling an attribute-weighting process that is contingent upon brands. The present study models this process based on consumer behavior theories and estimates the model using real market data.
\end{abstract}

Keywords Positioning, Brand experience, Brands, Negativity effect, Importance weight, Modeling consumer behavior

Paper type Research paper

C Hyun Young Park and Sue Ryung Chang. Published by Emerald Publishing Limited. This article is published under the Creative Commons Attribution (CC BY 4.0) licence. Anyone may reproduce, distribute, translate and create derivative works of this article (for both commercial and noncommercial purposes), subject to full attribution to the original publication and authors. The full terms of this licence may be seen at http://creativecommons.org/licences/by/4.0/legalcode

Both authors contributed equally to this work. The authors thank Dr. Wujin Chu at Seoul National University Business School for his help in the data collection process. This work was supported by the CEIBS Research Grant [number 3HMJA] from China Europe International Business School (CEIBS) and the Yonsei University Research Grant of 2020 [number 2020-22-0394].

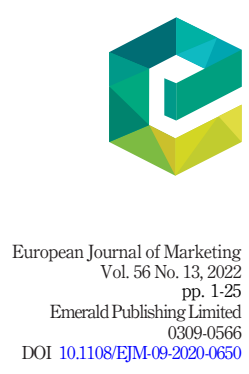


EJM

56,13

Brands constitute one of the most powerful forces shaping consumers' lives (Fitzsimons, 2015; Keller and Lehmann, 2006). Brands act as relationship partners for consumers, providing a sense of belongingness and helping them construct, express and affirm their desired identities (Aaker, 1999; Cova and Pace, 2006; Cutright et al., 2014; Escalas and Bettman, 2003, 2005; Fournier, 1998; Simmons, 2008). Indeed, past research has documented many positive impacts that brands can generate to firms by influencing consumer decisions, such as increased repeat purchases, product recommendations, willingness to forgive product failures, cross-selling, message persuasiveness and willingness to pay price premium (Aaker, 1996; Aaker et al., 2004; Baker et al., 2010; Carroll and Ahuvia, 2006; Ding and Tseng, 2015; Heinrich et al., 2012; Thomson et al., 2005).

Despite the prominent power that brands exert on consumer decisions, many prior studies modeling consumer decision processes have treated brands as a mere product attribute, parallel to price, color or size (Ding et al., 2011; Gilbride et al., 2006). Specifically, these past studies examined whether consumers placed more or less weight on brand information compared to other attribute information during their decision-making process, while assuming that the weight of each attribute was constant across brands. However, should brands be treated as equivalent to other product attributes? Can brands influence consumer decision processes - in particular, the importance weights placed on other product attributes - at a level different from those other attributes? It could be possible, for instance, for a consumer trying to purchase a flight ticket to weigh the importance of safety differently depending on the airline brand.

Compared to other product attributes, brand has a more "enriched" nature (Nowlis and Simonson, 1997) because its meaning is drawn from associated sources, including the brand's product attribute information, related marketing activities and consumers' experiences with the brand (Aaker, 1991; Ding and Tseng, 2015; French and Smith, 2013; Keller, 1993). Accordingly, several marketing gurus have referred to a brand as "the intangible sum of a product's attributes" (Ogilvy, 1985) or "a container for a customer's complete experience with the product" (Zyman, 2000). These insights suggest that a brand is a higher-order construct that should be distinguished from other product attributes. This conceptual distinction between a brand and other product attributes is important, because brands may function as "tinted eyeglasses through which consumers view products" (Keinan and Avery, 2008, p.2), impacting the extent to which consumers value product attributes (Ahluwalia, 2000, 2002; Erdem et al., 2002).

Building on these insights, we propose that brands, as a higher-order construct, can influence how consumers weigh the importance of various product attributes in their decision-making process. As a result, the importance weight of an attribute would differ across brands, resulting in a brand-contingent attribute-weighting process. To investigate when and how brands impact the importance weight of product attributes, we introduce a multi-level choice model in which brands can influence the importance weights at a level different from product attributes. In particular, we examine whether attribute weights are contingent upon the following two aspects of a brand: (1) the perceived position of a brand relative to its competitors; and (2) consumers' past brand usage experiences.

Using consumers' real purchase decision data linked with their survey data from an airline industry, we demonstrate that attribute importance weights are indeed contingent upon the perceived relative position of brands and consumers' past brand usage experiences. We find that when a brand is perceived to be inferior to its competition in a given attribute, the weight assigned to that attribute is increased for that brand. For instance, if consumers perceive the safety of airline brand A to be worse than that of competing brands, they would place a greater weight on the safety for brand A compared to 
other brands. In contrast, when consumers perceive a brand to be superior to its competitors in a given attribute, only consumers with extensive brand usage experiences place greater weight on that attribute for that brand.

The current research contributes to both theory and practice in several important ways. First, we advance the literature on consumer decision processes by proposing an attribute-weighting process that is contingent upon brands. Specifically, our research answers when and how brands influence the importance weights - that is, depending on the perceived relative position of a brand and consumers' past brand usage experiences. Second, we contribute to the limited body of marketing literature in which quantitative models are formulated based on theories from psychology and consumer behavior and then validated using real market data (Kopalle, 2015). Third, our findings provide managerial insights on whether marketers should prioritize highlighting the perceived superiority of their brand or improving the perceived inferiority compared to competing brands given their limited resources. Our results also validate the importance of segmenting customers based on the level of their brand usage experience.

Next, we review prior research that studied how consumers weigh the importance of product attributes in their choice process. We then propose our predictions on the brandcontingent attribute-weighting process based on the psychology and consumer behavior literatures. Afterwards, we specify our full model and present the estimation results that corroborate our proposition.

\section{Conceptual development and hypotheses}

Past research on attribute importance weights

Although many experimental studies have investigated the conditions under which attribute importance weights change, most did not study the impact of brands on these changes (Evangelidis and Levav, 2013; Irwin and Naylor, 2009; Kahn and Meyer, 1991; Kivetz and Simonson, 2000; Shapiro and Spence, 2002). Furthermore, in some of these studies, brand information was treated similar to other product attribute information (e.g., Kivetz and Simonson, 2000). As an exception, Nowlis and Simonson (1997) distinguished brand from another attribute (i.e. price) and conceptualized it as a relatively more enriched attribute. They revealed that brand [price] becomes more [less] important when evaluated separately than when evaluated jointly with other options - i.e. weights are contingent upon the decision mode. However, they did not explore the possibility that brand as a higher-order construct can influence the importance of other product attributes, which would result in different weights for one attribute (e.g. price) across brands even under a given decision mode.

Among behavioral works, Ahluwalia $(2000,2002)$ showed that people give different weights to the same information (e.g. the Clinton-Lewinsky affair) depending on their motivation or attachment to the target of evaluation (e.g. President Clinton). A few experiments were conducted in brand evaluation contexts and showed that brand-related factors, such as consumers' brand commitment or brand familiarity, change the weight given to brand information. However, these studies were conducted in the context of evaluating a single person or a product, rather than in a choice/purchase context involving multiple alternatives. Accordingly, the studies did not explore or suggest when or how attribute weights would differ across brands. Furthermore, brand-related factors were temporally primed (e.g. asked participants to take a positive stance for an unknown brand), instead of using consumers' existing, real brand commitment or brand familiarity. Hence, testing their impact using real market data in the context of consumer choice/purchase processes is still in need.

Past empirical modeling research examining consumers' decision strategies (e.g. weighted average, elimination by aspects, etc.) often examined importance weights of 
EJM

56,13

product attributes in consumer choice processes. However, the focus of this literature was not on exploring whether brands can change attribute importance weights. For instance, Gilbride and Allenby $(2004,2006)$ aimed at modeling screening rules that consumers adopted to eliminate alternatives based on specific attribute-level thresholds, and consequently, their models adopted an equal (i.e. non-contingent) importance weight across brands for each attribute, instead of brand-contingent attribute weights. Gilbride et al. (2006) treated brand as one of 16 attributes in their conjoint study to estimate their decision process model. Ding et al. (2011) also included brand as one of the product features when investigating which model of decision rules better predict how consumers formulate consideration sets. Because brand was treated as one of product attributes, these studies did not examine the possibility of brand-contingent attribute weights.

A limited number of studies on consumer decision processes have introduced the concept of "contingent weights." However, such weights were contingent upon decision contexts for instance, type of response mode (choice vs value matching; Tversky et al., 1988) and background information learned from previous choices (Tversky and Simonson, 1993) rather than brands. Furthermore, which attribute received a greater weight under a given response mode or choice context was "either assumed or assessed by a pretest" (Willemsen and Keren, 2002, p.646) rather than estimated using real market-place data. Dzyabura and Hauser (2019) used synthetic data to estimate a model for product recommendation in which consumers update product attribute weights during their product search. However, their research examined consumers' learning of attribute weights over time (i.e. the weights were contingent upon consumers' search), rather than brand-contingent attribute-weights.

In the empirical modeling literature, brand choice models based on panel data typically specify importance weights of product attributes (e.g. price or promotion sensitivity) parameters to be common across brands at the product category level (Guadagni and Little, 1983; Fader and Hardie, 1996; Mela et al., 1997; Villas-Boas and Winer, 1999). Although these models also include brandspecific intercepts to capture intrinsic values/equity of brands separately, most do not incorporate the effect of brands on attribute importance weights. Some studies formulated utility functions in a choice model or brand equity as a function of brand-related factors, such as brand credibility and brand inertia (de Oliveira et al., 2015; Erdem and Swait, 1998; Swait and Erdem, 2007). However, they also did not focus on how brands influence attribute importance weights. Indeed, only few quantitative modeling studies have incorporated brand-specific attribute importance weights (vs fixed weights across brands) and examined the "process" via which a brand can influence attribute importance in a consumer's choice process. Among the few works, Erdem et al. (2002) show that brand credibility can change the sensitivity (i.e. importance weight) of price in consumers' product choice processes. However, the effect of brand was limited to a single attribute (i.e. price) and was explored only from the brand credibility perspective. Thus, how different aspects of a brand other than its credibility influence attribute weights in a multi-attribute and multi-brand context has yet to be explored.

Our research adds to these few attempts that modeled and estimated consumer decision process using real market data to investigate when and how brands influence attribute importance weights in a multi-attribute and multi-brand choice context. Specifically, we propose an attributeweighting process that is contingent upon the two critical aspects of brand management: (1) the perceived relative position of a brand; and (2) consumers' brand usage experiences.

First, we examine the perceived relative position of a brand because (brand) positioning is considered to be the highlight or essence of the entire marketing process, guiding marketing mix plans (Kotler, 1997; Moore and Helstein, 2018). Due to this practical importance, several past decision process models that examined attribute weights have incorporated a closely related concept - i.e. relative advantage/disadvantage - into their models (Shafir et al., 1989, 
1993; Tversky and Simonson, 1993; see the model specification section for details on how we extend these models). Furthermore, existing psychology and consumer behavior findings (e.g. prospect theory, Kahneman and Tversky, 1979; negativity bias, Baumeister et al., 2001; Rozin and Royzman, 2001) enables us to predict how a brand's relative position would influence attribute weights.

Second, we examine consumers' brand usage experiences based on past research that helped us predict how our focal effect (i.e. the effect of perceived brand positioning on attribute weights) may be moderated by consumers' existing relationship with the brand (Ahluwalia, 2002; Chaiken et al., 1996). In those past studies, consumers' relationship with the brand has been denoted by brand familiarity or commitment, which are constructs conceptually related with brand usage experience (Alba and Hutchinson, 1987; Garbarino and Johnson, 1999; Ha and Perks, 2005). Brand familiarity or commitment is attitudinal or motivational construct that usually requires subjective scale measurements often vulnerable to reporting biases or exogenous manipulations. On the other hand, brand usage experience is a behavioral and observable construct that is prevalently adopted as firms' key performance indicator and can be measured more objectively (i.e. specific number of brand usage can be counted). Consequently, brand usage experience is more adequate for our study applying an empirical model using the real market data.

In the next two sections, we review relevant literatures from psychology and consumer behavior that helped us build our predictions on how (1) the perceived relative position of a brand and (2) consumers' brand usage experiences would impact attribute weights.

\section{Perceived relative position of a brand}

The concept of positioning was popularized by marketing professionals, Ries and Trout (1986), who defined it as "creating a position in a prospective customer's mind, one that reflects a company's own strengths and weaknesses as well as those of its competitors". Academics also construe that "a brand's position represents its location vis-à-vis its competitors in the mental maps" (Avery and Gupta, 2015, p. 4). Accordingly, the goal of positioning strategy is "to occupy a clear, distinctive, and attractive position relative to competing products in the minds of target consumers" (Sarvary and Elberse, 2006). All these definitions and goal of brand positioning indicate that a brand position refers to a perceived position in consumers' minds relative to competing brands.

To build hypotheses regarding how a brand's superior or inferior position in an attribute influences the importance of that attribute, we introduce past research on how people weigh positive information (relevant to superior position) and negative information (relevant to inferior position) differently. The value function of prospect theory, which illustrates that "losses loom larger than gains" (Kahneman and Tversky, 1979, p.279), imply that people place greater weight on negative information than on positive information. Consistent with the prospect theory, past psychology research provides vast amount of evidence for the greater weighting of negative information compared to similarly positive information in numerous contexts. For instance, after reviewing various streams of the psychology literature (e.g. impression formation, learning, emotions, etc.), Baumeister et al. (2001, p.323) concluded that the impact of "bad is stronger than good." Rozin and Royzman (2001)'s review concur that negative entities are more potent and dominant than positive entities, and they name this phenomenon negativity bias. This effect has also been observed in consumer contexts (e.g. greater impact of negative over positive product reviews; Basuroy et al., 2003; Chevalier and Mayzlin, 2006; Hennig-Thurau et al., 2014; Herr et al, 1991; Mizerski, 1982).

Past research offers several theoretical accounts for possible mechanisms underlying the negativity bias. First, negative information tends to be more diagnostic than positive information 
EJM

56,13

in forming related judgments. For instance, impression formation research has heavily documented that negative information (e.g. one dishonest behavior) is more useful than positive information (e.g. one honest behavior) in categorizing (or forming an impression about) a person as either bad or good, and thus negative information receives a greater weight (Fiske, 1980; Skowronski and Carlston, 1989). Likewise, in consumer contexts, product failure information is found to be more diagnostic than positive performance information in making product evaluations (Herr et al., 1991). Second, people encounter negative information less frequently than positive information - the sheer amount of the latter is greater than that of the former (Baumeister et al., 2001) - and this lower frequency in itself serves as useful information, as it indicates a change from the default of positive experiences (Fiske, 1980; Skowronski and Carlston, 1989; Chevalier and Mayzlin, 2006). Third, consumers tend to attribute the source of positive reviews to reviewers rather than to the positive performance of the product, whereas they tend to attribute negative information to the product or service itself (Chen and Lurie, 2013; Mizerski, 1982). As such, negative (vs. positive) information receives greater weight when making judgements and purchase decisions related to a product or service.

Altogether, these past findings suggest that consumers are likely to place greater importance on an attribute if a focal brand is perceived to be inferior to competing brands on that attribute. Accordingly, we propose that attribute weights will be contingent upon (i.e. increased by) a brand's position perceived to be inferior to its competitors:

H1. Consumers will increase the weight for a brand's attributes perceived to be inferior to those of competing brands (i.e. a significant brand-contingent negativity effect).

Because past research shows positive information is overweighed only under certain boundary conditions (Ahluwalia, 2002; Chaiken et al., 1996), we next move to introduce those boundary conditions (i.e. interaction effect) instead of making predictions about the main effect of brand-contingent positivity effect.

\section{Brand usage experience}

Despite the prevalence of negativity bias, past research have found important boundary conditions for this effect (Ahluwalia, 2002; Block and Keller, 1995; Kivetz and Ahluwalia, 2005; Maheswaran and Meyers-Levy, 1990). They found that consumers focus on negative information only when they are motivated to process information in-depth - for instance, when they are seriously involved in an issue (Maheswaran and Meyers-Levy, 1990), when the outcome promised by a message seems uncertain (Block and Keller, 1995) or when they are not at all familiar with a brand (Ahluwalia, 2002). Under these circumstances, consumers are motivated to make an accurate decision and thus are open to information of both valences (Ahluwalia, 2002; Chaiken et al., 1996), which in the end leads to overweighing of negative (vs positive) information due to the mechanisms explained in the previous section. Consequently, consumers with a limited brand experience who might be uncertain about or unfamiliar with the brand are likely to overweigh negative information.

In contrast, when consumers are familiar with the target of evaluation, they are no longer uncertain about the outcome and thus are not driven by the accuracy motivation. Instead, their pre-existing evaluation of the target directs how they process information, resulting in selective information processing that reinforces their pre-existing attitude (Ahluwalia, 2000, 2002; Chaiken et al.,1996; Ditto et al., 1998; Russo et al., 1998). That is, when their pre-existing attitude is negative [positive], consumers will place greater weight on negative [positive] information. This polarization effect occurs because pre-existing attitudes are motivated to defend those attitudes. In sum, consumers with extensive brand usage experience are likely to overweigh either negative or positive information depending on their pre-existing attitude toward the brand. 
Altogether, the findings suggest that negative information will be weighed heavily regardless of the level of consumers' brand experience, whereas positive information will be weighed heavily only when consumers have an extensive brand experience. When applied to our context of interest, we can expect that only the impact of a brand's superior position (i.e. the brand-contingent positivity effect) will depend on (i.e. be enhanced by) consumers' brand usage experiences. Thus, consumers with an extensive brand usage experience are likely to increase the weight of attributes that they perceive to be superior to those of competitors, whereas consumers with a limited brand usage experience are less likely to do so.

H2. As consumers' brand usage experience increases, they will give greater weight to attributes of a brand perceived to be superior to those of competing brands.

\section{Model specification}

To investigate when and how attribute importance weights are contingent upon brands, we present a two-level random coefficients multinomial logit model in which the importance weight of an attribute can vary across brands. Specifically, we model importance weights (i.e. the coefficients of product attributes in consumers' utility function) as a function of, thus to be contingent upon: (1) the perceived relative position of a brand; and (2) consumers' brand usage experience. Next, we explain the utility function of our model and the operationalization of our key variables in detail.

\section{Utility specification of a brand choice model}

We use a random-coefficient multinomial logit model to predict a brand choice among a set of alternatives. As in a typical discrete choice model, it is assumed that people choose the brand option of maximal utility and the utility maximization leads to a choice probability of each brand. We assume that consumers have an additive utility function for a brand choice and the utility that consumer $i$ obtains from choosing brand $j$ can be specified as a function of the perceived values of each attribute $\left(X_{i j m}\right)$ weighted by their correspondent importance $\left(\beta_{i j m}\right)$ as follows:

$$
U_{i j}=\sum_{m=1}^{M} X_{i j m} \beta_{i j m}+\varepsilon_{i j}, m=1,2, \ldots, M
$$

where $X_{i j m}$ is consumer $i$ 's subjective evaluation of attribute $m$ of brand $j$ and $\beta_{i j m}$ is the importance weight parameter of attribute $m$ of brand $j$ for consumer $i . M$ indicates the total number of product attributes. $\varepsilon_{i j m}$ is a random error that is independent and identically distributed extreme value. Using this utility function, we calculate the corresponding choice probability for brand $j$ using a typical method of simulated maximum likelihood for random coefficients multinomial logit model (McFadden and Train, 2000).

In this utility function, we allow the importance weights $\left(\beta_{i j m}\right)$ to vary not only across attributes and individuals, but also across brands. Next, we specify the brand-specific importance weight for each attribute $m\left(\beta_{\mathrm{ijm}}\right)$ as a function of (1) the perceived relative position of brands and (2) consumer's brand usage experiences.

\section{Perceived relative position of a brand}

We have hypothesized that the importance weight of an attribute can be influenced by the perceived position of a brand relative to its competing brands in consumer $i$ 's consideration set (i.e. inferior position; H1). Due to the managerial importance of brand positioning, several 
$\mathrm{EJM}$

56,13

Figure 1.

The main effects model past models have considered the impact of the perceived relative position of a brand (or of a choice option) when examining the impact of different attributes on a consumer's choice. For instance, Shafir et al. $(1989,1993)$ included relative advantage between available options as a component in their choice model. However, their model did not incorporate the contingent weighting process and was formulated specifically for binary choices between lotteries with two attributes. Tversky and Simonson (1993) introduced a model that captured the perceived tradeoff among multi-attribute products and incorporated a contingent weighting process. However, the attribute weights were not contingent upon the relative tradeoffs (i.e. the relative position of the options), but upon consumers' past choices. Furthermore, all of these past models did not examine the effect of relative advantage separately from the effect of relative disadvantage. Unlike these past models, we incorporate an attribute-weighting process that is contingent upon the perceived relative position of a brand. In addition, we separately specify perceived relative disadvantage (inferior position) and advantage (superior position) of a multi-attribute brand compared to its competitors because prior behavioral studies suggest that an increase in one of these effects might not mean a decrease in the other (Ahluwalia, 2002).

We model that the importance weight consumer $i$ places on attribute $m$ for brand $j$ [i.e. $\beta_{i j m}$ in equation (1)] is a function of the perceived inferior position and superior position of brand $j$ in attribute $m$ as follows:

$$
\begin{aligned}
\beta_{i j m}= & \alpha_{0 i m}+\alpha_{1}\left|X_{i j m}-\bar{X}_{i(-j) m}\right| \cdot I\left[X_{i j m}-\bar{X}_{i(-j) m}<0\right] \\
& +\alpha_{2}\left|X_{i j m}-\bar{X}_{i(-j) m}\right| \cdot I\left[X_{i j m}-\bar{X}_{i(-j) m}>0\right]
\end{aligned}
$$

While $\alpha_{0 i m}$ denotes the intrinsic importance of attribute $m$ for consumer $i$ (i.e. general attribute importance in the product category that is not contingent upon brand), all the other components of the equation indicate changes in the attribute weight contingent upon the perceived relative position of the brand. That is, our equation incorporates both the intrinsic importance and the importance contingent upon the context (i.e. a brand's position relative to competing brands in an attribute), following past research that considered both of these aspects for importance weights (Willemsen and Keren, 2002). This specification enables us to explore the process underlying the changes in attribute weights, beyond capturing the "global" changes in weights observed in past research (Tversky and Simonson, 1993). Figure 1 visually demonstrates our two-level model structure of the main effects model.

First-level: The utility function of brand choice model

$$
U_{i j}=\sum_{m=1}^{M} X_{i j m} \underbrace{}_{i j m}+\varepsilon_{i j} \quad \begin{aligned}
& i: \text { individual } \\
& j: \text { brand } \\
& m \text { : attribute }
\end{aligned}
$$

Second-level: The equation for importance weights

$$
\begin{aligned}
\beta_{i j m}=\alpha_{0 i m} & \left.+\alpha_{1}\left|X_{i j m}-\bar{X}_{i(-j) m}\right| \cdot I\left[X_{i j m}-\bar{X}_{i(-j) m}<0\right]\right\} \text { Brand-contingent negativity effect } \\
& \left.+\alpha_{2}\left|X_{i j m}-\bar{X}_{i(-j) m}\right| \cdot I\left[X_{i j m}-\bar{X}_{i(-j) m}>0\right]\right\} \text { Brand-contingent positivity effect }
\end{aligned}
$$

where $X_{i j m}-\bar{X}_{i(-j) m}$ : perceived relative position of brand $j$ in attribute $m$ for individual $i$ 
We express the perceived relative position of a brand for each attribute as $X_{i j m}-\bar{X}_{i(-j) m}$, which is the difference between the perceived value of attribute $m$ for consumer $i$ for brand $j$ and the mean of the perceived value of attribute $m$ for consumer $i$ across all the other brands (excluding brand $j$ ). This specification captures consumers' cognitive process, in which a consumer perceives a brand's positioning by comparing the brand's performance relative to a reference point that summarizes the relationship among all other brands competing in consumers' minds. Although past studies (Shafir et al., 1989, 1993; Tversky and Simonson, 1993) did not use the term "reference point" when specifying the relative advantage of an option, their specification of relative advantage is mathematically and conceptually similar to our specification that uses a reference point [1]. In our specification, the gist of the relationship among all the other brands is encoded as a reference point (i.e. $\bar{X}_{i(-j) m}$ : the mean evaluation of attribute $m$ of all the other brands) against which the focal brand's position is compared [2]. We take the absolute value of the perceived relative brand position in order to distinguish its magnitude effect from its directional effect as we explain next.

To separately estimate the effects of a brand's inferior position (H1) and superior position, the indicator components $I\left[X_{i j m}-\bar{X}_{i(-j) m}<0\right]$ and $I\left[X_{i j m}-\bar{X}_{i(-j) m}>0\right]$ are multiplied by the perceived relative brand position component. The brand-contingent negativity effect (H1) can be tested by examining the significance of $\alpha_{1}$ in equation (2). We did not hypothesize the brand-contingent positivity effect, but we control for it in our model and later empirically test it by examining the significance of $\alpha_{2}$.

\section{Interaction with consumers' brand usage experience}

To investigate the impact of consumers' brand usage experience on brand-contingent positivity and negativity effects, we add the interactions between the perceived brand position (i.e. each of the positivity and negativity terms) and consumers' brand usage experience to equation (2) as follows:

$$
\begin{aligned}
\beta_{i j m}= & \alpha_{0 i m} \\
& +\alpha_{1}\left|X_{i j m}-\bar{X}_{i(-j) m}\right| \cdot I\left[X_{i j m}-\bar{X}_{i(-j) m}<0\right] \\
& +\alpha_{2}\left|X_{i j m}-\bar{X}_{i(-j) m}\right| \cdot I\left[X_{i j m}-\bar{X}_{i(-j) m}>0\right] \\
& +\alpha_{3}\left|X_{i j m}-\bar{X}_{i(-j) m}\right| \cdot I\left[X_{i j m}-\bar{X}_{i(-j) m}<0\right] \cdot \text { BrandExperience }_{i j} \\
& +\alpha_{4}\left|X_{i j m}-\bar{X}_{i(-j) m}\right| \cdot I\left[X_{i j m}-\bar{X}_{i(-j) m}>0\right] \cdot \text { BrandExperience }_{i j} \\
& +\alpha_{5} \text { BrandExperience }_{i j}
\end{aligned}
$$

The interaction between the brand-contingent positivity effect and consumers' brand usage experience (H2) can thus be tested by checking the significance of $\alpha_{4}$ in equation (3). Although we did not hypothesize the interaction between the brand-contingent negativity effect and consumers' brand usage experience, we control for it in our model and later empirically test this by examining the significance of $\alpha_{3}$.

\section{Empirical results \\ Data}

For estimation, we used proprietary data collected by an Asian airline company as part of its internal consulting project. The airline provided flight services only for the routes between 
EJM

56,13

an island and mainland cities within an East Asian country at the time of data collection. Only two other airlines operated on the same domestic routes connecting the island and mainland then. The data included consumer survey data, which were linked with real flight purchase decision data. Specifically, the consumer survey was conducted in May 2007 at the check-in counter areas of the airport located on the island and the airports of the relevant mainland cities. The survey was distributed across different dates (weekdays and weekends) and times (morning and afternoon). Customers who completed the check-in process and held a boarding pass of one of the three airlines were approached for the survey. Hence, customers of all three airlines were included as the survey participants. As an incentive to complete the survey, customers were offered a gift set consisting of premium skincare products, which was actually sold at the duty-free shops of the airports at that time. When a customer agreed to participate in the survey, his/her current flight purchase information (i.e. their airline choice; the dependent variable in our discrete choice model) was recorded based on their boarding pass and a questionnaire marked with the airline code that matched the customer's airline choice was handed out. In this way, customers' real airline brand choice data and their survey data were linked and we estimated our model based on the real choice data. A total of 608 customers participated in the survey, of whom 311 completed all the questions necessary for our study. As a result, we used these 311 participants as the final sample for our main estimation. These 311 participants indicated that they had some experiences with all three airlines in the past - that is, they either boarded the airlines in the past or considered purchasing a ticket from them during an actual purchase process. Hence, they qualified as the sample for our research, in which they evaluated each of three airlines on various attributes.

The survey asked participants to rate the importance of various factors that they considered when they purchased their flight ticket on a five-point scale $(1=$ not at all important; 3 = neither important nor unimportant; 5 = very important). The factors included nine dimensions related to brand image (e.g. youthfulness, playfulness) and five attributes related to product quality (i.e. affordability, safety, service friendliness, cabin cleanliness and seat comfort). These latter five attributes were among the most commonly included criteria in the airline service quality evaluation literature (Wang et al., 2011 for a review) and were the attributes relevant to our interest for the present study. Four of these five quality-related attributes, excluding seat comfort, received an average importance rating of 4.5 or greater out of 5 , indicating that these attributes played very important roles in customers' flight ticket purchase decisions. Seat comfort received an importance rating of 4.26, still higher than many of other image-related dimensions which were mostly considered neither important nor unimportant. However, seat comfort was highly correlated with cabin cleanliness (correlation over 0.65). Considering a potential multi-collinearity problem when including the two variables, we excluded seat comfort whose importance rating was lower than that of cabin cleanliness and used the remaining four attributes in our main analyses.

After rating the general attribute importance, participants were asked to evaluate the three airlines on those product attributes on a five-point scale $(1=$ not at all, $5=$ very good). These attribute evaluation measures were used as a key independent variable (i.e. $X_{\mathrm{ijm}}$ : perceived value of attribute $m$ for consumer $i$ for brand $j$ ) in our model. Participants were also asked to indicate how many past usage experiences they had with the three airline companies. The survey also included other questions for the consulting project, such as participants' purpose of travel; methods of flight reservation; top of the mind airline brand; exposure to word of mouth related to the airlines; and demographic information such as age, gender, income level and education level. 
Figure 2 illustrates the customers' subjective evaluations of the three airlines on the four attributes (i.e. $X_{i j m}$ of our model averaged across participants), which were rated on a five-point scale $(1=$ not at all, $5=$ very good). Figure 3 more directly depicts the perceived relative differences among the three airlines in the four attributes that we modeled (i.e. $\mathrm{X}_{i j m}-\bar{X}_{i(-j) m}$ ). That is, they indicate the differences in the perceived attribute levels among the brands (e.g. difference in perceived affordability), not the differences in the objective attribute level (e.g. objective price difference). As the figures indicate, Airline $\mathrm{C}$ shows quite different attribute ratings and perceived relative position compared to Airline A and Airline B. Specifically, Airline C occupies a low-fare position, while Airlines A and B occupy a more premium position in customers' minds. This overall customer perception reflects the actual ticket price and services offered by the three airlines. Airline $\mathrm{C}$ offered substantially lower ticket prices and operated on smaller aircrafts compared to the two other airlines. It was also the first airline in the country to eliminate free in-flight meals.

\section{Model results}

We estimate two models:

(1) Model 1 for testing the main effects of inferior position and superior position on attribute importance weights; and

(2) Model 2 for testing the interaction effects between consumers' brand usage experience and each of the main effect terms.

For cross-validation, we divided a sample of 311 customers into in-sample and out-of-sample

groups and report the goodness-of-fit statistics in Table 1. The log-likelihood and Akaike

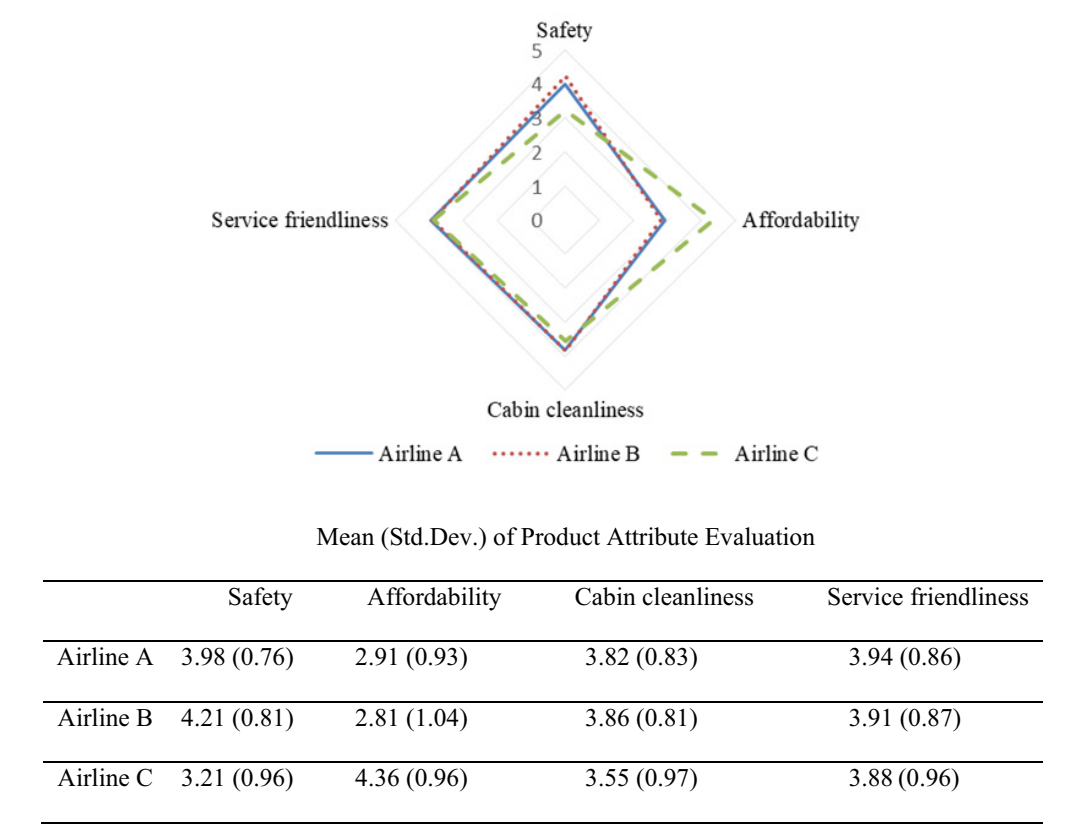

Mean (Std.Dev.) of Product Attribute Evaluation

\begin{tabular}{lcccc}
\hline & Safety & Affordability & Cabin cleanliness & Service friendliness \\
\hline Airline A & $3.98(0.76)$ & $2.91(0.93)$ & $3.82(0.83)$ & $3.94(0.86)$ \\
\hline Airline B & $4.21(0.81)$ & $2.81(1.04)$ & $3.86(0.81)$ & $3.91(0.87)$ \\
\hline Airline C & $3.21(0.96)$ & $4.36(0.96)$ & $3.55(0.97)$ & $3.88(0.96)$ \\
\hline
\end{tabular}

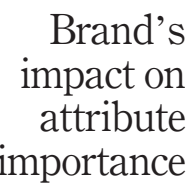

11

Figure 2.

Evaluation of three airline brands on four attributes 
EJM

56,13

12

Figure 3.

Perceived relative differences among the airline brands

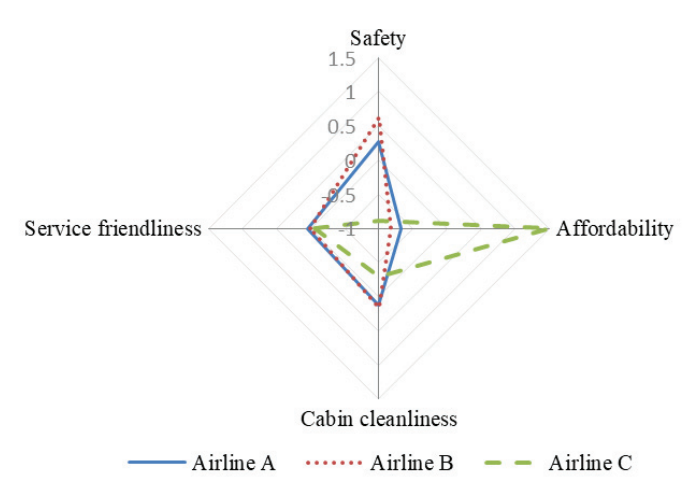

Mean (Std.Dev.) of Perceived Relative Differences

\begin{tabular}{lcccc}
\hline & Safety & Affordability & Cabin cleanliness & Service friendliness \\
\hline Airline A & $0.27(0.63)$ & $-0.67(0.78)$ & $0.12(0.73)$ & $0.05(0.70)$ \\
\hline Airline B & $0.62(0.85)$ & $-0.83(0.95)$ & $0.17(0.78)$ & $-0.00(0.85)$ \\
\hline Airline C & $-0.89(1.04)$ & $1.50(1.35)$ & $-0.29(1.07)$ & $-0.05(1.07)$
\end{tabular}

Information Criterion (AIC) statistics in Table 1 are smaller for Models 1 and 2 than the baseline model (without the brand-contingent weighting process) in both in-sample and out-of-sample results. Thus, the models with brand-contingent weighting process (i.e. Model 1 and Model 2) provide a better fit to our dataset than the baseline model (i.e. non-contingent weighting model). This implies that using brand-contingent weights is important in predicting consumers' brand choices.

Table 2 presents the estimation results of our two models [3]. The parameter estimates in Table 2 offer insights on when and how importance weights change across brands. First, the Model 1 column shows that the coefficient of the brand-contingent negativity effect was

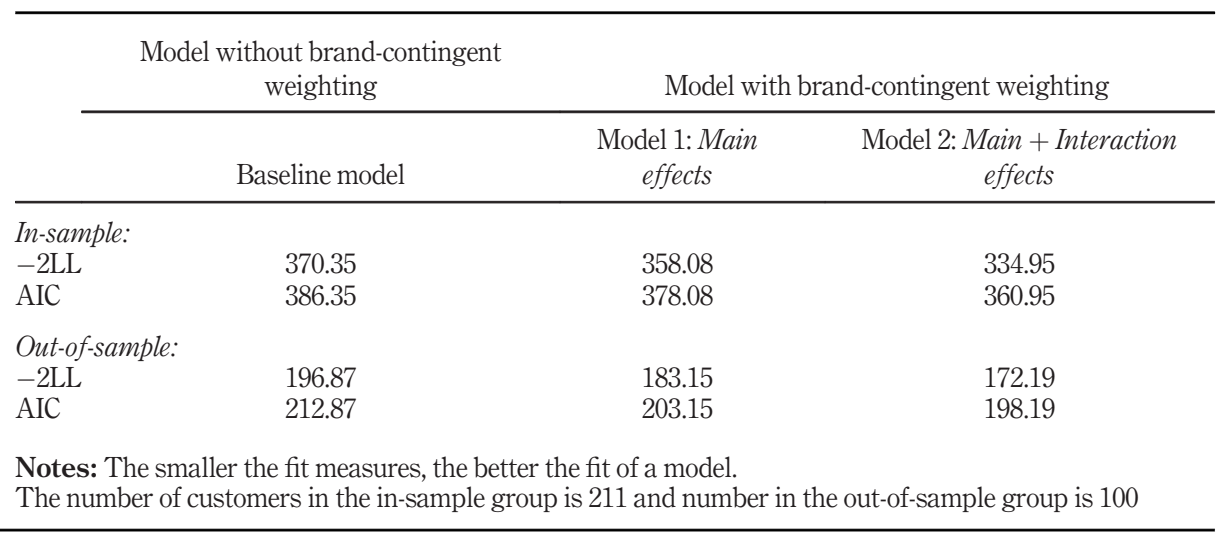

Table 1.

Goodness-of-fit statistics

The number of customers in the in-sample group is 211 and number in the out-of-sample group is 100 
significant and positive $\left(\alpha_{1}=0.118, p=0.008\right)$. Consistent with $H 1$, consumers in general placed greater weight on an attribute when a brand was perceived to be inferior to competing brands for that attribute. For instance, if a consumer perceived Airline A to be worse in safety and Airline B to be worse in cabin cleanliness compared to competitors, the consumer placed a greater weight on safety when evaluating Airline A and on cabin cleanliness when evaluating brand $\mathrm{B}$. In contrast, the coefficient for brand-contingent positivity effect was not significant $\left(\alpha_{2}=-0.019, p=0.550\right)$. That is, consumers in our sample did not increase the weight for a brand's attributes that they perceived to be superior to those of competing brands.

Note that the individual-level intrinsic importance of each attribute $\left(\alpha_{0 \mathrm{im}}\right)$ was estimated as random effects. The mean attribute importance estimate indicates the intrinsic attribute importance after controlling for the effect of brand position and brand usage experience. As a result, it is possible to get a negative coefficient as in the case of cabin cleanliness $(-0.632)$. The results implies that cabin cleanliness is intrinsically less important in the airline industry on average compared to other attributes with positive coefficients (e.g. $\bar{\alpha}_{O}$, affordability $=1.640$ ). In addition, the standard deviation of the intrinsic importance of only one attribute, affordability, was significant $(\mathrm{SD}=1.090, p=0.005)$. This indicates that there was variability in importance of affordability (i.e. price factor) across consumers, which makes sense considering the wide variation in price sensitivity of consumers in general.

Model 2 column in Table 2 presents the results of the interaction model that tested the impact of consumers' brand usage experience on brand-contingent negativity and positivity effects. The brand-contingent negativity effect did not interact with brand usage experience $\left(\alpha_{3}=0.015, p=.116\right)$. In fact, the main effect of the brand-contingent negativity remained significant even when the interaction term was included $\left(\alpha_{1}=0.107, p=0.014\right)$. In contrast, supporting $H 2$, the brand-contingent positivity effect depended on consumers' past brand usage experience $\left(\alpha_{4}=0.010, p=0.045\right)$. That is, as consumers' brand usage experience

\begin{tabular}{|c|c|c|}
\hline Parameter estimate & $\begin{array}{c}\text { Model } 1 \\
\text { Main effects }\end{array}$ & $\begin{array}{c}\text { Model } 2 \\
\text { Model } 1+\text { interaction effects }\end{array}$ \\
\hline \multicolumn{3}{|l|}{ The main effect of brand position } \\
\hline Negativity (inferior position) & $0.118(0.044)^{* * *}$ & $0.107(0.043)^{* *}$ \\
\hline Positivity (superior position) & $-0.019(0.033)$ & $-0.021(0.032)$ \\
\hline \multicolumn{3}{|l|}{ The interaction with brand usage experience } \\
\hline Negativity x Brand usage experience & & $0.015(0.010)$ \\
\hline Positivity x Brand usage experience & & $0.010(0.005)^{* *}$ \\
\hline Brand usage experience & & $-0.005(0.004)$ \\
\hline \multicolumn{3}{|l|}{ Intrinsic attribute importance } \\
\hline Mean attribute importance - Safety & $0.486(0.243)^{\text {*** }}$ & $0.405(0.200)^{* *}$ \\
\hline Mean attribute importance - Affordability & $1.640(0.467)^{\text {**** }}$ & $1.687(0.486)^{* * * *}$ \\
\hline Mean attribute importance - Service friendliness & $0.603(0.270)^{* *}$ & $0.654(0.266)^{* * *}$ \\
\hline Mean attribute importance - Cabin cleanliness & $-0.632(0.220)^{* * * *}$ & $-0.591(0.205)^{* * *}$ \\
\hline Standard deviation - Safety & $0.325(0.221)$ & $0.467(0.223)^{* * *}$ \\
\hline Standard deviation - Affordability & $1.090(0.387)^{\text {**** }}$ & $1.183(0.483)^{* *}$ \\
\hline Standard deviation - Service friendliness & $0.366(0.225)$ & $0.408(0.180)^{* * *}$ \\
\hline Standard deviation - Cabin cleanliness & $0.626(0.431)$ & $0.105(0.198)$ \\
\hline AIC & 559.066 & 557.550 \\
\hline
\end{tabular}

Notes: The AIC of the baseline model without the brand-contingent weighting process is $565.148 .{ }^{* * * *} p<$ $0.01, * * * 0.05$ based on two-tailed tests. Standard errors are shown in parentheses

\section{Brand's impact on attribute importance \\ importance}

13 
$\mathrm{EJM}$

56,13

increased, they gave greater weight to attributes of a brand perceived to be superior to those of competing brands.

Following up with the significant interaction, we conducted spotlight analyses at each level of brand usage experience to examine how the brand-contingent positivity effect changed at different levels of consumers' brand usage experience (Krishna, 2016; Spiller et al., 2013). The analyses revealed that only consumers who had 14 or more brand usage experiences in the past showed a significant brand-contingent positivity effect (all $p$ 's $<$ 0.032; Table 3). On the other hand, consumers who had four or fewer usage experiences showed either a marginal or significant reversed brand-contingent positivity effect (all $p$ 's $<$ 0.091; Table 3). Altogether, the results indicate that when a consumer perceives a brand to be superior to its competitors in an attribute, the consumer's repeated brand usage experience magnifies the importance weight he/she places on that attribute for that brand (H2).

Although the interaction between the brand-contingent negativity effect and consumers' brand usage experience was not significant, we conducted supplementary spotlight analyses at each level of brand usage experience to better understand the brand-contingent

Table 3.

The spotlight analyses at different levels of brand usage experience

\begin{tabular}{|c|c|c|c|c|c|c|c|}
\hline \multirow{2}{*}{$\begin{array}{c}\text { Brand } \\
\text { Usage } \\
\text { Experience }\end{array}$} & \multicolumn{3}{|c|}{ Positivity Effect } & \multirow{2}{*}{$\begin{array}{c}\text { Brand } \\
\text { Usage } \\
\text { Experience }\end{array}$} & \multicolumn{3}{|c|}{ Negativity Effect } \\
\hline & $\begin{array}{l}\text { Parameter } \\
\text { Estimate }\end{array}$ & S.E. & $\mathrm{P}>|\mathrm{z}|$ & & $\begin{array}{c}\text { Parameter } \\
\text { Estimate }\end{array}$ & S.E. & $\mathrm{P}>|\mathrm{z}|$ \\
\hline 1 & $-.975^{* *}$ & .474 & .040 & 1 & $1.356^{* *}$ & .618 & .028 \\
\hline 2 & $-.832^{* *}$ & .422 & .049 & 2 & $1.371^{* *}$ & .617 & .026 \\
\hline 3 & $-.726^{*}$ & .435 & .095 & 3 & $1.231^{*}$ & .645 & .056 \\
\hline 4 & $-.547^{*}$ & .324 & .091 & 4 & $1.400^{* *}$ & .618 & .023 \\
\hline 5 & -.380 & .262 & .147 & 5 & $1.232^{* *}$ & .540 & .023 \\
\hline 6 & -.088 & .131 & .503 & 6 & $1.564^{* *}$ & .732 & .033 \\
\hline$\square$ & $\square$ & $\square$ & $\square$ & $\square$ & $\square$ & $\square$ & $\square$ \\
\hline 10 & -.183 & .340 & .590 & 10 & $1.679^{* *}$ & .796 & .035 \\
\hline 11 & -.559 & .632 & .377 & 11 & $1.574^{* *}$ & .686 & .022 \\
\hline 12 & -.536 & .425 & .207 & 12 & $1.906^{* *}$ & .917 & .038 \\
\hline 13 & .309 & .289 & .286 & 13 & $1.734^{* *}$ & .830 & .037 \\
\hline 14 & $.996^{* *}$ & .437 & .023 & 14 & $1.704^{* *}$ & .830 & .040 \\
\hline 15 & $.937^{* * *}$ & .404 & .020 & 15 & $2.343^{* *}$ & 1.072 & .029 \\
\hline 16 & $.810^{* *}$ & .325 & .013 & 16 & $1.614^{* *}$ & .669 & .016 \\
\hline$\square$ & $\square$ & $\square$ & $\square$ & $\square$ & $\square$ & $\square$ & $\square$ \\
\hline 20 & $.831^{* *}$ & .387 & .032 & 20 & $1.619^{*}$ & .829 & .051 \\
\hline$\square$ & $\square$ & $\square$ & $\square$ & $\square$ & $\square$ & $\square$ & $\square$ \\
\hline 30 & $3.602^{* *}$ & 1.424 & .011 & 30 & $1.981^{* *}$ & .954 & .038 \\
\hline$\square$ & $\square$ & $\square$ & $\square$ & $\square$ & $\square$ & $\square$ & $\square$ \\
\hline 50 & $4.526^{* *}$ & 1.829 & .013 & 50 & $3.389^{* *}$ & 1.801 & .031 \\
\hline
\end{tabular}

Notes: The colored rows indicate that the negativity effect and/or the positivity effect are either significant $(p<.05)$ or marginal $(p<.10)$ at the corresponding level of consumers' brand usage experience. ${ }^{* *} p<.05, " p<.10$ based on two-tailed tests. 
negativity effect across different levels of consumers' brand usage experience. The analyses revealed that the brand-contingent negativity effect was either significant or marginal at all levels of brand usage experience (all p's $<0.056$; Table 3 ). Thus, regardless of whether consumers had limited or extensive brand experience, consumers placed a greater weight on an attribute of a brand if the brand was perceived to be inferior to its competitors in that attribute.

Robustness check (a): testing weights based on within-brand, across-attributes evaluations So far, we assumed that the relative position is perceived by comparing a brand against other competing brands on each attribute - an assumption taken from past research (Tversky and Simonson, 1993). However, it could also be possible that attribute importance weights are influenced by the evaluation of a brand conducted across attributes per brand, instead of the evaluation conducted across brands separately per attribute. According to past research on alternative-based processing, consumers can evaluate whether an alternative (i.e. a brand in our context) is strong or weak in certain attributes even when the alternative is evaluated on its own, prior to comparing it to other alternatives in a choice process (Bettman et al., 1998). Therefore, as a robustness check, we verified whether attribute weights are contingent upon a brand's position perceived from the within-brand, acrossattributes evaluation.

Similar to the reference point of our main model to which the focal brand's performance in an attribute was compared (i.e. $\left|X_{i j m}-\bar{X}_{i(-j) m}\right|$; within-attribute, across-brand comparison), we modeled that consumers would perceive a brand to be particularly strong or weak in a certain attribute by comparing its performance in one attribute against its performances in all other attributes (i.e. $\left|X_{i j m}-\bar{X}_{i j(-m)}\right|$; within-brand, across-attribute evaluation). As we did in our main analysis, we then multiplied this component with the two indicator functions that separately estimated the main effect of attribute superiority and inferiority (compared to other attributes, perceived from a within-brand evaluation) on importance weights. We replaced the original variables with these new variables to test the attribute-weighting process contingent upon the brand position inferred from the withinbrand, across-attribute evaluation. We also tested another extended model that included both the original variables and the new variables to allow for the attribute-weighting process that is contingent upon both the relative brand position perceived within an attribute (i.e. original variables), and the position of a brand inferred based on the withinbrand, across-attribute evaluation (i.e. new variables).

We tested these two extended models and their parameter estimates are reported in Table A1 of Appendix 1. We found that the goodness-of-fit (AIC) of the first extended model (including only the new variables) was larger (570.361) than that of our original main effects model (559.066; Model 1 in Table 2), which implies that our original model outperforms the first extended model with new variables. Furthermore, none of the new variables were significant in the extended model (all $p$ 's $>0.528$ ), indicating that the attribute importance weights did not vary depending on the brand position perceived from an across-attribute comparison conducted within the brand. Adding the original variables to these new variables (extended Model 2) improved the AIC (561.314), but the original main effects model still fitted the data better. Furthermore, in the second extended model, none of the new variables were significant (all $p$ 's $>0.790$ ), whereas the original variable denoting the inferior relative brand position had a significant impact on attribute importance weights (i.e. the significant brand-contingent negativity effect; $p=0.0008$ ) even when the new variables were included. The results supported that attribute weights are contingent upon the perceived position of a brand relative to its competitors. Although consumers may be able to evaluate a brand's strength or weakness by 
$\mathrm{EJM}$

56,13

comparing its own performance across different attributes (instead of comparing against other brands), we did not find this evaluation to influence weights assigned to corresponding attributes.

\section{Robustness check (B): replication in the beer brand choice context}

To validate whether our findings generalize to brand choices in other product categories, we recruited 2,468 US beer drinkers through Amazon Mechanical Turk (MTurk) and tested our models using survey data on beer brand choice [4]. Based on the results from a pretest $(N=$ 278; see Appendix 2 for details on the pretest), our main survey included the top five beer brands that MTurk participants had most drinking experiences with: Bud Light, Miller, Coors, Budweiser and Corona. In the main survey, 948 (out of 2,468) participants indicated that they had past experiences of drinking all of those five beer brands.

After indicting whether they had drinking experiences with each of the five target beer brands, participants evaluated the five brands on five product attributes on a five-point scale $(1=$ not good at all, $5=$ very good). The attributes included flavor, mouthfeel, alcohol contents, bitterness and price, which were selected out of thirteen attributes based on the pretest results (see Appendix 2 for more details). Next, participants were asked which beer brand they would choose in their next beer purchase. They could choose one of the five target brands or an "other" brand. This brand choice was used as the dependent variable in our multinomial logit model estimation. We measured brand usage experience of participants by asking the number of beer purchases they made in the recent one year for each of the five target brands and for the brands other than the five.

Using the beer choice survey data, we estimated the same two models (i.e. Model 1 and Model 2) as in the airline data analysis. The results supported our proposed brandcontingent weighting process. Specifically, the brand-contingent negativity effect was positive and significant $\left(\alpha_{1}=0.327, p=0.000\right)$. Also, the interaction between the perceived superior brand position and consumers' brand usage experience was positive and significant $\left(\alpha_{4}=0.007, p=0.008\right)$. Note that the brand-contingent positivity effect (i.e. the main effect), and the interaction between the perceived inferior brand position and brand usage experience were not significant (see Table A2 of Appendix 2 for the results details).

\section{General discussion}

Although brands are considered to be among the most important intangible assets of many firms (Keller and Lehmann, 2006), past research that modeled consumer choice processes treated brands as product attributes similar to price, size and color (Ding et al., 2011; Gilbride et al., 2006). In contrast, we distinguished brand from other product attributes as a higherorder construct that can influence the importance consumers place on those other attributes during their choice processes. We model this brand-contingent attribute-weighting process by introducing a two-level choice model, in which two aspects of a brand - the perceived relative position of a brand and consumer's past experiences with the brand - influence attribute importance weights. Using consumers' real flight purchase data linked with their survey data, we estimated our proposed model and demonstrated that the importance weight for an attribute does differ across brands. Specifically, the weight of an attribute was increased when the brand under consideration was perceived to be inferior to its competitors in the given attribute (i.e. brand-contingent negativity effect). This effect was observed regardless of the level of past experiences consumers had with the brand. In contrast, the perceived superior position of a brand in a given attribute increased the importance of that attribute for that brand (i.e. brand-contingent positivity effect) only when consumers had extensive past experiences with the brand. 


\section{Theoretical contributions}

Our findings contribute to the literature in several important ways. First, we advance the decision process literature by introducing a brand-contingent attribute-weighting process. Although both practitioners and academics considered brands as a more enriched concept compared to other product attributes (Ogilvy, 1985; Zyman, 2000; Keller, 1993; Nowlis and Simonson, 1997), no extant research treated brands as a "higher-order construct" and examined the process via which brands can affect importance weights of various product attributes (i.e. a two-level attribute-weighting process) in a multi-attribute, multi-brand choice context. The current research introduces a model to answer when and how attribute importance weights change due to brands. To answer this question, we examined the impact of brand positioning on attribute importance weights that no past research has studied despite its managerial importance and also introduced a possible moderating factor (i.e. brand usage experience).

Second, we refined the existing understanding of the prospect theory (Kahneman and Tversky, 1979) by formulating a unique quantitative model in a multi-brand choice context and revealing a possible boundary condition of the theory. Specifically, we distinguished inferior attributes from superior attributes and examined their separate effects on attribute importance weights, unlike past models that did not distinguish these effects (Shafir et al., 1989, 1993; Tversky and Simonson, 1993). Consistent with the prospect theory, our findings show that, in general, consumers are aversive of inferior aspects of a brand and place greater weight on inferior attributes than on superior attributes. Importantly, however, we discovered that the greater weighting of inferior attributes is observed mostly among consumers with limited brand usage experiences. As brand usage experience increases, weights for superior attributes increase and may even become greater than weights for inferior attributes. Indeed, our spotlight analysis showed that, as consumers accumulated brand usage experiences, the increase rate for the weights of superior attributes became greater than that for the weights of inferior attributes. This result suggests that gains can loom larger than losses for consumers with extensive brand usage experiences and they may become less aversive of the brand's inferior attributes. This is consistent with the past finding that consumers committed to a brand are motivated to defend the brand, and consequently, they weigh positive brand information more than negative information (Ahluwalia, 2000, 2002; Chaiken et al.,1996). Because consumers with extensive brand usage experiences (i.e. consumers with many repeat purchase occasions) are highly likely to be committed with the brand, they would increase the weights for superior attributes more than inferior attributes to defend the brand. By demonstrating the gradual changes in attribute weights depending on various levels of brand usage experiences, we enrich the existing understanding of the prospect theory.

Finally, we contribute to the limited body of research that proposed a behavioral theorydriven statistical model and then validated it using real market data with actual purchase information. Although a few prior studies have proposed quantitative models based on consumer behavior literature and empirically tested them (Gilbride and Allenby, 2004, 2006, Ding et al., 2011), past research that took such an approach is still limited (Kopalle, 2015).

\section{Managerial implications}

The brand-contingent attribute-weighting process suggests that attributes consumers consider important may differ depending on brands even if the brands operate in the same product category. Specifically, attributes that consumers generally perceive to be important when purchasing a product may not be as important for certain brands, while those attributes can be critically important for other brands. Hence, discerning which attributes 
EJM

56,13

18

target consumers perceive to be highly important for a specific brand is necessary so that a firm can invest its limited marketing resources more on improving consumers' perception of those attributes. On the other hand, if some consumers think of their need for a product (not the brand) first and screen out brands based on the general attribute importance for the category to form a consideration set, firms may need to improve the perceived quality of attributes generally important in the category at least to the level that lets their brands included in the consideration set, while also investing on attributes that consumers perceive important specifically for the brand.

Second, our significant brand-contingent negativity effect suggests the importance of enhancing consumer perceptions of inferior attributes (e.g. by using communication plans or improving the actual attribute). Because brand positioning involves seeking to occupy a distinctive and attractive position relative to competing brands, it naturally leads practitioners to focus on distinguishing a brand from the competition by highlighting the attributes in which the brand is more attractive than its competitors. Interestingly, however, our findings suggest that consumers care about inferior aspects of a brand more than the extent that marketers believe consumers do. Enhancing the perceived inferiority may be especially important when attributes of a brand show strong brand-contingent negativity effect (i.e. increased weights for those attributes) and as a result weights of other - in particular, superior - attributes are relatively decreased. Unless the entire category becomes homogenous once all brands in the market has improved their inferior attributes, firms are recommended to invest in improving attributes perceived as inferior by their target consumers.

Finally, the significant interaction between consumers' brand usage experience and brand-contingent positivity effect implies that customers with extensive experiences can be targeted with messages highlighting the perceived superiority of a brand as well as messages improving the perceived inferiority of that brand concurrently because these customers would consider information of both valences important (compared to customers with limited experiences who tend to care more for negative information). For instance, brands with price advantage, such as JetBlue and Walmart, can consider sending targeted messages to frequent customers emphasizing their superior aspects (i.e. price advantage) as well as enhancing inferior aspects (e.g. premium wine selection for JetBlue or organic product offerings for Walmart). On the other hand, to attract new customers or customers with only few usage experiences, more effort can be placed on enhancing the perceived inferiority of the brand (e.g. product/service quality of JetBlue and Walmart).

\section{Limitations and directions for future research}

Future research can extend the current model by exploring different ways that consumers perceive a brand's relative position. For example, we assumed that consumers use the mean attribute value of competing brands as a reference point in perceiving the relative position of the focal brand. This assumption was based on past models that calculated relative advantage of an option against all other alternatives in the choice set (Shafir et al., 1989, 1993; Tversky and Simonson, 1993; see footnote 1). Although, in our model section, we explained the advantages of using the mean of competing brands as a comparison point over other possible reference or comparison points (e.g. the maximum or the minimum, which indicates the best or worst performing brand in the given attribute), it is still possible that consumers may adopt other relational heuristics to identify the comparison point. Future research can explore different types of reference points and conditions under which one type is preferred over another. These insights can be incorporated into the current model to better reflect consumers' actual decision-making processes. 
Another possible area for future research is to investigate how the brand-contingent weighting process changes when the choice options in a consumers' consideration set include multiple products of the same brand. The current research focused on brand purchase situations in which each brand represented a choice alternative. However, our model can be extended to situations in which a choice set consists of multiple options under the same brand. In such a case, the change in attribute weight caused by the perceived relative brand position may be similar for the options under the same brand, especially if the brand positioning is clear in consumers' minds and as a result the perceived differences between options with the same brand are minimal (e.g. color difference between two iPhones). Alternatively, it is also possible that the relative position of the brand is perceived differently between two options with the same brand, thus resulting in different importance weights for the given attribute between the two options. It would be interesting for future research to examine which of these expectations is supported.

Future research can also examine the boundary conditions of the brand-contingent attribute-weighting process. One possible condition is when the number of brands under consideration is significantly increased. In this case, consumers may engage in a brandcontingent attribute-weighting process only in the final choice stage, after the majority of brands have been screened out, because engaging in the brand-contingent attributeweighting process could be cognitively burdensome in the preliminary decision stage including an extensive number of brands.

Finally, contextual factors, such as differences in industry or geographical market or sample size, may alter our findings. Future research can examine whether the brandcontingent weighting process varies depending on such factors.

\section{Notes}

1. The past studies assumed that consumers perceive the relative advantage of an option by going through multiple rounds of pairwise comparisons among all possible pairs in the choice set. Such pairwise comparisons among three brands, for example, can be specified as $X_{i 1 m}-X_{i 2 m}$ and $X_{i 1 m}-X_{i 3 m}$ when comparing brand 1 against the other two brands. And the sum of these comparisons is $2 \mathrm{X}_{\mathrm{ilm}}{ }^{-}$ $\left(\mathrm{X}_{\mathrm{i} 2 \mathrm{~m}}+\mathrm{X}_{\mathrm{i} 3 \mathrm{~m}}\right)$, which is equivalent to $\left(\mathrm{X}_{\mathrm{ilm}}-\bar{X}_{\mathrm{i}(-1) \mathrm{m}}\right)$ of our model once divided by 2 . Thus, our variable can also be considered to base on pairwise comparisons in nature.

2. We propose the mean as a reference point because, unlike the median, it takes into account the precise value of each attribute, which is critical in brand choice contexts. Also, the mean is more appropriate than the maximum or minimum (i.e. the best or the worst performing brand in a given attribute), because adopting maximum or minimum values of alternative options as the reference point would hinder us from separately estimating the effects of relative disadvantage and relative advantage.

3. Considering our small sample size, Table 2 presents the model results based on the full sample data (all 311 customers) instead of the in-sample data. However, using the in-sample data provides exactly the same results as using the full data.

4. While individual consumers' real brand choice (i.e. purchase information) was used in the airline data estimation, real choice information was not available for the beer survey data due to the innate self-report nature of the survey. Specifically, the beer survey measured a hypothetical future choice (i.e. which beer brand participants would choose in their next purchase occasion). Since contextual factors at the point of purchase may alter consumers' brand choice, we reported the results of the beer survey only as a robustness check.

\section{References}

Aaker, D.A. (1991), Managing Brand Equity, The Free Press, New York, NY. 
$\mathrm{EJM}$

56,13

Aaker, D.A. (1996), "Measuring brand equity across products and markets", California Management Review, Vol. 38 No. 3, pp. 102-121.

Aaker, J.L. (1999), “The malleable self: the role of self-expression in persuasion”, Journal of Marketing Research, Vol. 36 No. 1, pp. 45-57.

Aaker, J.L., Fournier, S. and Brasel, S.A. (2004), "When good brands do bad", Journal of Consumer Research, Vol. 31 No. 1, pp. 1-16.

Ahluwalia, R. (2000), "Examination of psychological processes underlying resistance to persuasion", Journal of Consumer Research, Vol. 27 No. 2, pp. 217-232.

Ahluwalia, R. (2002), "How prevalent is the negativity effect in consumer environments?", Journal of Consumer Research, Vol. 29 No. 2, pp. 270-279.

Alba, J.W. and Hutchinson, J.W. (1987), "Dimensions of consumer expertise", Journal of Consumer Research, Vol. 13 No. 4, pp. 411-454.

Avery, J. and Gupta, S. (2015), "Brand positioning", in Gupta, S (Ed.), Core Curriculum Readings, Harvard Business Publishing. New York, NY.

Baker, W.E., Sciglimpaglia, D. and Saghaf, M. (2010), "Branding of post-purchase ancillary products and services: an application in the mobile communication industry", European Journal of Marketing, Vol. 44 No. 5, pp. 547-566.

Basuroy, S., Chatterjee, S. and Abraham Ravid, S. (2003), "How critical are critical reviews? The box office effects of film critics, star power, and budgets", Joumal of Marketing, Vol. 67 No. 4, pp. 103-117.

Baumeister, R.F., Bratslavsky, E., Finkenauer, C. and Vohs, K.D. (2001), "Bad is stronger than good", Review of General Psychology, Vol. 5 No. 4, pp. 323-370.

Bettman, J.R., Luce, M.F. and Payne, J.W. (1998), “Constructive consumer choice processes”, Journal of Consumer Research, Vol. 25 No. 3, pp. 187-217.

Block, L.G. and Keller, P.A. (1995), "When to accentuate the negative: the effects of perceived efficacy and message framing on intentions to perform a Health-Related behavior", Journal of Marketing Research, Vol. 32 No. 2, pp. 192-203.

Carroll, B. and Ahuvia, A. (2006), "Some antecedents and outcomes of brand love", Marketing Letters, Vol. 17 No. 2, pp. $79-89$.

Chaiken, S., Giner-Sorolla, R. and Chen, S. (1996), "Beyond accuracy: defense and impression motives in heuristic and systematic information processing”, in Gollwitzer, PM. and Bargh, JA. (Eds) The Psychology of Action: Linking Cognition and Motivation to Behavior, Guilford, New York, NY, pp. 553-578.

Chen, Z. and Lurie, N.H. (2013), "Temporal contiguity and negativity bias in the impact of online word of mouth", Journal of Marketing Research, Vol. 50 No. 4, pp. 463-476.

Chevalier, J.A. and Mayzlin, D. (2006), "The effect of word of mouth on sales: online book reviews", Journal of Marketing Research, Vol. 43 No. 3, pp. 345-354.

Cova, B. and Pace, S. (2006), "Brand community of convenience products: new forms of customer empowerment - the case "my nutella the community", European Journal of Marketing, Vol. 40 No. 9/10, pp. 1087-1105.

Cutright, K.M., Erdem, T., Fitzsimons, G.J. and Shachar, R. (2014), "Finding brands and losing your religion?”, Journal of Experimental Psychology: General, Vol. 143 No. 6, pp. 2209-2222.

De Oliveira, M.O.R., Silveira, C.S. and Luce, F.B. (2015), "Brand equity estimation model”, Journal of Business Research, Vol. 68 No. 12.

Ding, C.G. and Tseng, T.H. (2015), "On the relationships among brand experience, hedonic emotions, and Brand equity", European Journal of Marketing, Vol. 49 No. 7/8, pp. 994-1015.

Ding, M., Hauser, J.R., Dong, S., Dzyabura, D., Yang, Z., Chenting, S. and Gaskin, S.P. (2011), "Unstructured direct elicitation of decision rules", Journal of Marketing Research, Vol. 48 No. 1, pp. 116-127. 
Ditto, P.H., Scepansky, J.A., Munro, G.D., Marie Apanovitch, A.-. and Lockhart, L.K. (1998), "Motivated sensitivity to preference-inconsistent information", Journal of Personality and Social Psychology, Vol. 75 No. 1, pp. 53-69.

Dzyabura, D. and Hauser, J.R. (2019), "Recommending products when consumers learn their preference weights", Marketing Science, Vol. 38 No. 3, pp. 417-441.

Erdem, T. and Swait, J. (1998), "Brand equity as a signaling phenomenon", Journal of Consumer Psychology, Vol. 7 No. 2, pp. 131-157.

Erdem, T., Swait, J. and Louviere, J. (2002), "The impact of brand credibility on consumer price sensitivity", International Journal of Research in Marketing, Vol. 19 No. 1, pp. 1-19.

Escalas, J.E. and Bettman, J.R. (2003), "You are what they eat: the influence of reference groups on consumer connections to brands", Journal of Consumer Psychology, Vol. 13 No. 3, pp. 339-348.

Escalas, J.E. and Bettman, J.R. (2005), "Self-construal reference groups and brand meaning”, Journal of Consumer Research, Vol. 32 No. 3, pp. 378-389.

Evangelidis, I. and Levav, J. (2013), "Prominence versus dominance: how relationships between alternatives drive decision strategy and choice", Journal of Marketing Research, Vol. 50 No. 6, pp. 753-766.

Fader, P.S. and Hardie, B.G.S. (1996), "Modeling consumer choice among SKUs", Journal of Marketing Research, Vol. 33 No. 4, pp. 442-452.

Fiske, S.T. (1980), "Attention and weight in person perception: the impact of negative and extreme behavior", Journal of Personality and Social Psychology, Vol. 38 No. 6, pp. 889-906.

Fitzsimons, G. (2015), “5 Things I know about marketing - Duke’s Gavan Fitzsimons”, available at: www.msi.org/articles/5-things-i-know-about-marketing-dukes-gavan-fitzsimons/

Fournier, S. (1998), "Consumers and their brands: developing relationship theory in consumer research", Journal of Consumer Research, Vol. 24 No. 4, pp. 343-373.

French, A. and Smith, G. (2013), "Measuring Brand association strength: a consumer based Brand equity approach", European Journal of Marketing, Vol. 47 No. 8.

Garbarino, E. and Johnson, M.S. (1999), "The different roles of satisfaction, trust, and commitment in customer relationships", Journal of Marketing, Vol. 63 No. 2, pp. 70-87.

Gilbride, T.J. and Allenby, G.M. (2004), "A choice model with conjunctive, disjunctive, and compensatory screening rules", Marketing Science, Vol. 23 No. 3, pp. 391-406.

Gilbride, T.J. and Allenby, G.M. (2006), "Estimating heterogeneous EBA and economic screening rule choice models", Marketing Science, Vol. 25 No. 5, pp. 494-509.

Gilbride, T.J., Allenby, G.M. and Brazell, J.D. (2006), "Models for heterogeneous variable selection", Marketing Science, Vol. 23 No. 3, pp. 391-406.

Guadagni, P.M. and Little, J.D.C. (1983), "A logit model of brand choice calibrated on scanner data", Marketing Science, Vol. 2 No. 3, pp. 203-238.

Ha, H.-Y. and Perks, H. (2005), "Effects of consumer perceptions of brand experience on the web: brand familiarity, satisfaction and Brand trust", Journal of Consumer Behaviour, Vol. 4 No. 6, pp. 438-452.

Heinrich, D., Albrecht, C.M. and Bauer, H.H. (2012), "Love actually? Measuring and exploring consumers' Brand love", " in Consumer-Brand Relationships-Theory and Practice, Routledge, London, 137-150.

Hennig-Thurau, T., Wiertz, C. and Feldhaus, F. (2014), "Does twitter matter? The impact of microblogging word of mouth on consumers' adoption of new movies", Journal of the Academy of Marketing Science, Vol. 43 No. 3, pp. 375-394.

Herr, P.M., Kardes, F.R. and Kim, J. (1991), "Effects of word-of-Mouth and product-attribute information on persuasion: an accessibility-diagnosticity perspective", Journal of Consumer Research, Vol. 17 No. 4, pp. 454-462. 
$\mathrm{EJM}$

56,13

Irwin, J.R. and Naylor, R.W. (2009), "Ethical decisions and response mode compatibility: weighting of ethical attributes in consideration sets formed by excluding versus including product alternatives", Journal of Marketing Research, Vol. 46 No. 2, pp. 234-246.

Kahn, B.E. and Meyer, R.J. (1991), "Consumer multiattribute judgments under attribute-weight uncertainty", Journal of Consumer Research, Vol. 17 No. 4, pp. 508-522.

Kahneman, D. and Tversky, A. (1979), "Prospect theory: an analysis of decision under risk", Econometrica, Vol. 47 No. 2, pp. 263-291.

Keinan, A. and Avery, J.J. (2008), "Understanding brands”, Harvard Business School Module Note 509-041.

Keller, K.L. (1993), “Conceptualizing, measuring, and managing Customer-Based Brand equity”, Journal of Marketing, Vol. 57 No. 1, pp. 1-22.

Keller, K.L., (2006), "Brands and branding: research findings and future priorities", Marketing Science, Vol. 25 No. 6, pp. 740-759. and D.R. and Lehmann.

Kivetz, R., (2005), "Negativity in the evaluation of political candidates", Journal of Marketing, Vol. 69 No. 1, pp. 131-142.and R. and Ahluwalia.

Kivetz, R. and Simonson, I. (2000), "The effects of incomplete information on consumer choice”, Journal of Marketing Research, Vol. 37 No. 4, pp. 427-448.

Kopalle, P. (2015), "Modeling consumer behavior, research curation”, available at: https://academic.oup. com/jcr/pages/modeling_consumer_behavior

Kotler, P.H. (1997), Marketing Management: Analysis, Planning, and Control, 9th ed.: Prentice-Hall Englewood Cliffs, NJ.

Krishna, A. (2016), "A clearer spotlight on spotlight: understanding, conducting and reporting”, Journal of Consumer Psychology, Vol. 26 No. 3, pp. 315-324.

Lerro, M., Marotta, G. and Nazzaro, C. (2020), "Measuring consumers' preferences for craft beer attributes through Best-Worst scaling", Agricultural and Food Economics, Vol. 8 No. 1, p. 1.

McFadden, D. and Train, K. (2000), "Mixed MNL models for discrete response", Journal of Applied Econometrics, Vol. 15 No. 5, pp. 447-470.

Maheswaran, D. and Meyers-Levy, J. (1990), "The influence of message framing and issue involvement", Journal of Marketing Research, Vol. 27 No. 3, pp. 361-367.

Mela, C.F., Gupta, S. and Lehmann, D.R. (1997), "The Long-Term impact of promotion and advertising on consumer Brand choice", Journal of Marketing Research, Vol. 34 No. 2, pp. 248-261.

Mizerski, R.W. (1982), "An attribution explanation of the disproportionate influence of unfavorable information”, Journal of Consumer Research, Vol. 9 No. 3, pp. 301-310.

Moore, M.C. and Helstein, R. (2018), "Positioning: the essence of marketing strategy", Darden Case No. UVA-M-0754. Darden Business Publishing.

Nowlis, S.M. and Simonson, I. (1997), "Attribute - task compatibility as a determinant of consumer preference reversals”, Journal of Marketing Research, Vol. 34 No. 2, pp. 205-218.

Ogilvy, D. (1985), Ogilvy on Advertising, Vintage, New York, NY.

Ries, A. and Trout, J. (1986), Positioning: The Battle for Your Mind, McGraw-Hill, New York, NY.

Rozin, P. and Royzman, E.B. (2001), "Negativity bias, negativity dominance, and contagion", Personality and Social Psychology Review, Vol. 5 No. 4, pp. 296-320.

Russo, J.E., Meloy, M.G. and Medvec, V.H. (1998), "Predecisional distortion of product information", Journal of Marketing Research, Vol. 35 No. 4, pp. 438-452.

Sarvary, M. and Elberse, A. (2006), "Market segmentation, target market selection, and positioning", Harvard Business School Module Note 9-506-019.

Shafir, E.B., Osherson, D.N. and Smith, E.E. (1989), "An advantage model of choice”, Journal of Behavioral Decision Making, Vol. 2 No. 1, pp. 1-23. 
Shafir, E.B., Osherson, D.N. and Smith, E.E. (1993), "The advantage model: a comparative theory of evaluation and choice under risk", Organizational Behavior and Human Decision Processes, Vol. 55 No. 3, pp. 325-378.

Shapiro, S. and Spence, M.T. (2002), "Factors affecting encoding, retrieval, and alignment of sensory attributes in a Memory-Based Brand choice task", Journal of Consumer Research, Vol. 28 No. 4, pp. 603-617.

Simmons, G. (2008), "Marketing to postmodern consumers: introducing the internet chameleon", European Journal of Marketing, Vol. 42 No. 3/4, pp. 299-310.

Skowronski, J.J. and Carlston, D.E. (1989), "Negativity and extremity biases in impression formation: a review of explanations", Psychological Bulletin, Vol. 105 No. 1, pp. 131-142.

Spiller, S.A., Fitzsimons, G.J., Lynch, J.G., Jr,. and McClelland, G.H. (2013), "Spotlights, floodlights, and the magic number zero: simple effects tests in moderated regression", Journal of Marketing Research, Vol. 50 No. 2, pp. 277-288.

Swait, J. and Erdem, T. (2007), "Brand effects on choice and choice set formation under uncertainty", Marketing Science, Vol. 26 No. 5, pp. 679-697.

Thomson, M., MacInnis, D.J. and Whan Park, C. (2005), "The ties that bind: measuring the strength of consumers' emotional attachments to brands", Joumal of Consumer Psychology, Vol. 15 No. 1, pp. 77-91.

Tversky, A. and Simonson, I. (1993), "Context-dependent preferences”, Management Science, Vol. 39 No. 10, pp. 1179-1189.

Tversky, A., Sattath, S. and Slovic, P. (1988), "Contingent weighting in judgment and choice", Psychological Review, Vol. 95 No. 3, pp. 371-384.

Villas-Boas, J.M. and Winer, R.S. (1999), "Endogeneity in brand choice models”, Management Science, Vol. 45 No. 10, pp. 1324-1338.

Wang, R., Hsu, S.-L., Hsu Lin, Y. and Tseng, M.-L. (2011), "Evaluation of customer perceptions on airline service quality in uncertainty", Procedia - Social and Behavioral Sciences, Vol. 25, pp. 419-437.

Willemsen, M.C. and Keren, G. (2002), "Negative-based prominence: the role of negative features in matching and choice", Organizational Behavior and Human Decision Processes, Vol. 88 No. 2, pp. 643-666.

Zyman, S. (2000), The End of Marketing as We Know It, Harper and Collins, New York, NY.

\section{Further reading}

De Chernatony, L. and Dall'Olmo Riley, F. (1998), "Modelling the components of the brand”, European Journal of Marketing, Vol. 32 No. 11/12, pp. 1074-1090. 
$\mathrm{EJM}$

56,13
Appendix 1

\section{4}

Table A1.

Parameter estimates of the robustness check (A) models

Parameter estimate

AIC

The main effect of brand position

Negativity (inferior position perceived from

across-brand comparison)

Positivity (superior position perceived from across-brand comparison)

Inferior position perceived from an across-

attribute comparison

Superior position perceived from an across-

attribute comparison

\section{Intrinsic attribute importance}

Mean attribute importance - Safety

Mean attribute importance - Affordability

Mean attribute importance - Service friendliness

Mean attribute importance - Cabin cleanliness

Standard deviation - Safety

Standard deviation - Affordability

Standard deviation - Service friendliness

Standard deviation - Cabin cleanliness

$0.252(0.147)^{*}{ }^{*}$
$1.179(0.201)^{\text {**** }}$
$0.285(0.170)^{\text {**** }}{ }^{*}$
$-0.612(0.168)^{*}$
$0.311(0.187){ }^{* *}$
$0.518(0.226)^{* *}$
$0.092(0.276)$
$0.050(0.336)$

570.361
Robustness check

Model 2

includes brand positions perceived from both across-attribute comparisons and acrossbrand comparisons

Notes: ${ }^{* * * *} p<0.01,{ }^{* * *} p<0.05, \stackrel{*}{p}<0.10$ based on two-tailed tests.

Standard errors are shown in parentheses

\section{Appendix 2}

Robustness check (B): replication in the beer brand choice context

Pretest details. We recruited a separate group of participants from Amazon Mechanical Turk (MTurk; $N=278$ ) and conducted a pretest that asked whether participants had past experiences of drinking the top seven beer brands based on the US beer market share in 2020 by Euromonitor International. Because participants in the main survey had to evaluate beer attributes for each of the target brands included in the survey, we wanted to ensure that participants had drinking experiences with all of those brands so that they were able to give attribute evaluations for each brand. The pretest showed that only $8 \%$ of the MTurk participants have drunk two of the seven brands (i.e. Modelo and Busch). Accordingly, the main survey included only the top five beer brands that MTurk participants had most drinking experiences with: Bud Light, Miller, Coors, Budweiser and Corona.

The pretest also asked to what extent participants considered various beer attributes important when they purchase beer $(1=$ not at all important; $3=$ moderately important; $5=$ extremely important). Thirteen attributes were included in the pretest based on a past study measuring beer attributes (Lerro et al., 2020) and Craft Beer Academy (Patrick, 2012): color, aroma, flavor, mouthfeel, 
alcohol content, bitterness, price, country of origin, special grains, fermentation process (high/low fermentation), packaging size, packaging material (glass/can) and certification (organic). Participants indicated that only five of these attributes were more than moderately important on average when purchasing beer (i.e. importance rating of 3 or greater out of a five-point scale). Thus, in the main survey, we included only those five attributes: flavor, mouthfeel, alcohol contents, bitterness and price.

\section{Brand's impact on attribute importance}

Model 2

Parameter estimate

Model $1+$ interaction effects

The main effect of brand position

Negativity (inferior position)

Positivity (superior position)

Negativity $\times$ Brand usage experience

Positivity $\times$ Brand usage experience

Brand usage experience

$$
\begin{gathered}
0.327(0.058)^{\text {***** }} \\
0.005(0.022) \\
-0.005(0.009) \\
0.007(0.003)^{\text {**** }} \\
0.007(0.008)
\end{gathered}
$$

Intrinsic attribute importance

Mean attribute importance - Flavor

Mean attribute importance - Mouthfeel

Mean attribute importance - Alcohol content

Mean attribute importance - Bitterness

Mean attribute importance - Price

Standard deviation - Flavor

Standard deviation - Mouthfeel

$1.968(0.197)^{* * * *}$

$0.372(0.182)^{* *}$

$-0.234(0.168)$

$-0.251(0.123)^{* * *}$

$-0.856(0.132)^{* * * *}$

$2.526(0.318)$

$-1.414(0.212)^{* * *}$

$0.247(0.224)$

Standard deviation - Alcohol Content

Standard deviation - Bitterness

Standard deviation - Price

$-0.252(0.185)$

$-0.011(0.287)$

AIC

1968.66

Table A2.

Parameter estimates of the robustness check (B) model

Notes: ${ }^{* * * *} p<0.01,{ }^{* *} p<0.05, * p<0.10$ based on two-tailed tests.

Standard errors are shown in parentheses

\section{Corresponding author}

Hyun Young Park can be contacted at: hpark@ceibs.edu

For instructions on how to order reprints of this article, please visit our website: 